Australian Journal of

Educational Technology

\title{
The Perth Educational Television Project
}

\section{Ron Oliver, Mike Grant and Geoff Younger Edith Cowan University}

\begin{abstract}
The Perth Educational Television (PET) Project delivered educational television to schools in Perth during 1993 through a narrowcast system using Multipoint Distribution System (MDS) technology. A comprehensive program of 200 hours of television was delivered from Edith Cowan University and beamed through the metropolitan area of Perth in a trial project that investigated the potential of a pay TV service for education. This paper describes the context in which the PET Project was undertaken. It discusses the organisation and activity within the participating schools and investigates the value, potential and viability of future educational pay TV systems.
\end{abstract}

Television is a powerful medium that pervades a large portion of our daily living. Television sets can be found in 99\% of Australian homes (Herrington, 1993) and television viewing is an activity that is performed willingly and extensively by vast numbers of the population. In homes, television is used primarily for information and entertainment. Television viewing is an activity that requires little skill or effort for participation. The nature and content of the programming of television makes it an activity that is stimulating and highly enjoyable to the broadest crosssections of the population.

The high levels of television saturation within homes is also mirrored in schools and educational institutions. Up to $90 \%$ of schools in the United Kingdom use television in their educational programs (Moss, Gunter \& Jones, 1991) and similar levels of saturation are evident in the schools of other developed countries. Television is a powerful tool for teaching and learning but many factors act to limit the extent and scope of television as a learning tool in schools (Sumner, 1991). High among these factors is the level of access to quality educational programs (Ornstein, 1990; Moss et al.; 1991; Forsslund, 1991). This paper reports on a project in Western Australia that investigated alternative means for the delivery of quality television programs in educational settings. 


\section{Educational Television}

Many people hold different views on the advantages and opportunities that television offers society. The dominating influence of television on the cultures of many developed countries is seen as a reason for serious concern among writers (eg., Postman, 1984; Batra, 1987). Much of the concern comes from the number of hours that children spend viewing television; in the USA, it is estimated that by the time many children graduate from high school, they will have watched TV for up to 15,000 hours, and this is more time than is spent doing anything else except sleeping (Witt, 1979; Honig, 1983). Other concerns stem from the often violent nature of many of the programs and the passive and isolating methods of viewing (eg., Salomon, 1984; Holifield, 1992).

Educational television on the other hand appears to hold considerable potential to significantly enhance the quality of instructional programs in schools. Television can act as a powerful learning medium. It is a critical component of open and distance education programs where it serves to supplement print-based curriculum offerings in a variety of forms. In classroom teaching, it provides the capacity to extend classroom boundaries to outside worlds and events, it can provide concrete examples of abstract ideas and can encourage reflection and thinking on the part of students (Bates, 1988).

\section{Educational Technologies}

Schools and education systems are great users of technology. As new technologies emerge and become available to the consumer market, education markets are quick to embrace the technology to determine the possible advantages that might be derived. The speed with which education embraces new technologies is matched only by the speeds with which old technologies are dropped. This practice of adopting and dropping has led many to observe that few of the technologies ever seem to be able to live up to their true potential and to deliver the full educational advantage that they promised (Cuban, 1986).

This situation has caused many writers to reflect on the nature of technology, the media that result and the influence of the media themselves on the teaching and learning process. Research in this direction has demonstrated clearly, the tendency for educational practice to focus more on the media than the message that is being conveyed and for this reason, is distracted in the quest for better teaching and learning by the vehicles that are able to deliver this (Clark, 1983). That educational television is a valuable and resource for teaching and learning, is not in dispute. There is however a tendency for many people to overlook the potential and capabilities of this technology as new technologies emerge (Kozma, 1991). 


\section{Applications of Educational Television}

Educational television remains a powerful teaching and learning tool despite advancements in other technologies. There have been many studies into the use of educational television. The findings frequently demonstrate that in order to be a successful learning tool, educational television usage must embrace more than just viewing episodes (eg., Kozma, 1991; Catchpole, 1993). Teachers who assume that the television can teach and that children can learn by simply viewing, are not likely to achieve course aims. Learning from television is dependent on how a program is viewed and different people view television differently (eg., Salomon, 1984; Bates, 1988). Some viewers are reflective while others are not. Effective teaching leads students to analyse and reflect as they view and uses follow-up activities to consolidate and rehearse (eg., Ornstein, 1990; Holifield, 1992).

Patterns of usage of educational television have demonstrated a number of factors that influence the uptake and usage of programs in curriculum implementations. Forsslund (1991) describes some conditions that have been found to enhance the use of broadcast television in school settings:

- increased access to equipment,

- regular transmission slots that are in accord with school timing,

- better fit to the curriculum, basis for follow-up discussion

- series of programs that pursue instructional goals across a series of episodes,

- information on programs delivered to teachers in advance of screenings

- supplementary and guide materials to support broadcast programs.

\section{MDS Transmission System}

It was with such information in mind that the Perth Educational Television Project was devised. The Media Division at Edith Cowan University had been providing educational television for rural schools for many years and there appeared to be a potential market in local schools for specialist educational programming. An innovative means for delivering these programs was available in the Multipoint Distribution System (MDS). MDS is a one-way transmission by microwave of radio, television and data over distances of up to $50 \mathrm{~km}$. The transmitter is installed in a high location to optimise reach and the signal is received by means of an inexpensive antenna and down converter which in the case of television reception, connects directly into a television receiver by means of a normal $75 \mathrm{ohm}$ coaxial cable (Bahr, 1993). 


\section{Television in WA Secondary Schools}

A survey was conducted among a representative sample of local secondary schools to investigate patterns of usage of educational television and the likely uptake among local schools of a pay-TV service. The survey was conducted with the assistance of the library and resource staff within schools who assumed responsibility for the coordination and recording of television programming for classroom use. Questionnaires and interviews were administered in twenty schools. Feedback indicated a relatively high level of usage being made of video and television in classroom teaching. There were few teachers interviewed who did not hold educational television in high regard as a teaching and learning tool. There was universal support for the medium across all departments and a recognition that it had many strengths in educational settings. Teachers recognised the need for effective teaching practice to accompany educational use of the medium. Interestingly, the number of teachers in the schools who had used or made regular use of educational television, far exceeded the number who used computer-based technologies in their teaching / learning programs.

\section{Applications}

Teachers gave many reasons for the popularity of educational television as a teaching and learning medium. Among these responses were such observations as:

- Students respond very well to instruction and teaching through this medium.

- A class will attend en-masse to videos while that same class will be distracted and disruptive during direct teacher instruction.

- Video corresponds to elements of students' preferred learning styles where strong visual materials are frequently more stimulating than discussion or reading.

- Videos have the capacity to stimulate many learners where conventional materials may not.

- Students spend considerable time viewing television and video materials in their private lives and are accustomed to information input from this source.

Patterns of viewing were consistent across all schools. Viewing of direct broadcasts was rarely done. There were a number of reasons for this:

- most of the programs in the educational television category of broadcasting are aimed at a younger viewing audience,

- there is little flexibility in secondary school subject timings and frequently class times do not match broadcast times,

- much of the suitable television is broadcast in the evenings as a normal component of television programming, 
- secondary teachers expressed a desire to view programs before they incorporate them into their programs,

- the need for direct curriculum application meant even when all the previous conditions were favourable, the teachers still required the broadcast program to suit their immediate curriculum needs.

The most prevalent form of usage of this technology was with prerecorded programs in video-cassette recorders. Within all schools, there were portable display units comprising a VCR and large screen monitor. With schools of populations 500-1000 students, it was not uncommon to find up to 15 VCRs. A significant number of teachers in each school claimed to use videos as instructional tools more than once per week. The VCR machines tended to be organised and managed by separate subject departments and were placed on mobile trolleys to facilitate movement around the school.

\section{Organisation of Resources}

Video collections were organised in all schools as a library resource. Videos were accessioned and stored on the computerised library system. Programs were often recorded from broadcast television services. When a staff member judged that a broadcast program would be a useful instructional tool, library staff could be requested to make the recording. Most schools had a video collection that contained only limited titles. Library budgets were used to purchase commercial tapes to supplement library stocks. Schools were observed to be rationalising much of their existing AV materials, eg slides, $16 \mathrm{~mm}$ (and older videos) and were looking to video to replace these stocks. The schools all expressed an intention to build this part of their collection but were limited by the availability of suitable broadcast programs and the cost of commercial titles.

There were similar patterns of usage evident among the teachers in the schools that were surveyed:

- most tended to use the same programs from year to year in their teaching,

- video selection for classroom use was made early in the planning stages of the course being delivered,

- teachers preferred not to change their planned teaching programs,

- when new videos were incorporated into their teaching, this was done only after a preview screening and its suitability confirmed,

- videos were integrated into the teaching programs and built into lessons rather than used as supplementary or fill-in activities.

The level of student access and use of tapes varied between the schools. In most schools, the tapes were kept with the main collection and catalogued 
along with all other materials in the electronic library catalogue system. Most schools allowed students to use the tapes on machines set aside for this purpose in the library. A small number of schools had quite open policies on tape usage and allowed students to borrow tapes to use at home. There were quite restrictive practices in other schools where video tapes were not stored with the main collection and reserved solely for the use of the teaching staff. The main reason for this was to enhance the security of the tapes and to prevent the instance of students having previously viewed tapes that were to be used in instructional settings.

In most schools, there were small collections of video materials within some subject departments. For example, the English departments often held a collection of video tapes that were kept separately from other resources in the school. These tapes were typically, recordings of movies, films and plays that were studied in the English courses.

\section{Increased Opportunities}

Interviews with staff revealed that educational television was generally considered a valuable teaching medium. Many teachers were keen to make increased use of the medium but were impeded by a lack of suitable titles and the large costs associate with purchasing more titles. It was also evident that many teachers were not actively seeking to increase the level of educational television in their teaching but were quite optimistic that this could occur if they had access to broader ranges of titles.

In this climate, the opportunity for an independent broadcaster delivering educational television into local schools seemed ripe. Video collections in schools were limited and in need of expansion. There was an established infrastructure within schools to cater for the delivery and recording of new titles. If the costs to the schools could be kept to a minimum and a suitable range of programs selected and offered, there was a strong chance that schools would respond well and that this project could meet an educational need.

\section{The PET Project}

The Perth Educational Television (PET) Project saw educational television being delivered to schools in Perth through a narrowcast system using Multipoint Distribution System (MDS) technology. The MDS system was being used by the $T A B$ to deliver racing results and broadcasts to the agencies throughout the Perth metropolitan area. This system provided a narrowcast facility that extended across the Perth region. The signals were broadcast from the tallest building in the Perth Central Business District with a delivery radius of up to $65 \mathrm{~km}$. The flatness of the Perth region makes it ideally suited to MDS as a transmission system. 
The use of the existing MDS system for the PET Project required the cooperation of a number of key players. Contact was made with CFM Technology, the owners of the system and permission gained for use of the system for educational broadcasting. It was planned to deliver programs each school day morning when the system was not being used by its commercial owner. Stage One of the PET Project was planned as a trial across the third and fourth terms of 1993. The cooperation of the Telecom Television Centre was gained to enable the programs to be delivered from the Edith Cowan University Media Centre through the fibre-optic network to the transmitter. Finally the cooperation was sought from a number of publishers to gain permission for the inclusion of titles from their publications in the project. A number of live-to-air programs produced in the studios of the Edith Cowan University Media centre were also planned for inclusion.

A comprehensive program was selected for distribution, and Stage One of the project involved the delivery of 200 hours of television over the period of 2 terms in second semester 1993. The Project was a joint venture between Edith Cowan University, Telecom, WA Ministry of Education, the Department of Employment, Vocational Education and Training and CFM Technology.

There were a number of aims in Stage One of the PET Project:

- to investigate the potential of a user-pays system for delivering educational television to schools,

- to test MDS as a delivery system for educational broadcasting,

- to determine the capacity of schools to manage and coordinate receiving and delivery of the educational programs,

- to investigate potential changes to patterns of educational television usage among schools.

A program was established for Stage One comprising of series of episodes in the following subject areas:

- Media Studies

- English and Communication Studies,

- Introduction to Computer Applications (live-to-air)

- Mathematics Statistics (live-to-air)

- Live Science (live-to-air)

- Business Studies

- Social Studies

- Art

- Music 
The entire program each Friday was given to delivering programs aimed at the professional development of teachers in schools. These programs included a broad range of topics; for example, pastoral care, oral communications, the National Curriculum, education for the nineties.

Invitations were sent to secondary schools in the Perth Metropolitan area inviting participation. The costs to the participants was limited to the purchase and installation of the receiving equipment. This amounted to approximately $\$ 1200$. There was buy-back option for the participating schools. If they chose to leave the project at a later date, the equipment could be returned and a proportion of the expenditure recouped. The number of participants in Stage One was kept small. Eight schools and institutions were involved. This group was comprised of one independent secondary school, three senior high schools, two senior colleges (schools offering post-compulsory courses only), a TAFE centre and the Casuarina Prison. The necessary receiving equipment was installed in time for the broadcasts to commence in August 1993. In most settings, the equipment was installed in the library building and linked to existing audio-visual equipment. Stage One continued from the commencement of third term in August until the completion of fourth term in December.

\section{Outcomes}

Organisation and implementation of the educational television delivered by Stage One of the PET Project was closely monitored within schools by researchers from the University. This was to enable outcomes to be determined and to allow the utility and efficacy of the system to be properly assessed. The following section of the paper describes the delivery and distribution of the educational television within schools.

\section{Recording and Distribution}

There were several modes employed within schools to organise the recording and distribution of the programs. Schools received a detailed viewing guide of all programs being delivered. The guide provided the viewing dates and times, a description of each program, its subject and audience potential and duration in minutes. A common practice was for the library staff to distribute descriptions of the programs to senior staff in the schools and to receive from the various subject departments, details of the programs that were to be recorded. Once the required programs had been selected, the library staff established a system of recording the programs, creating descriptive covers for the cassettes and entering details of the new programs into the schools electronic library catalogue system. 


\section{Organisation}

The management of the program recording, cataloguing and distribution was performed by staff in the library. The typical process was:

- once the program booklet had been received, photocopy the pages to distribute a copy to each Head of Department (HOD) with the relevant programs highlighted,

- receive directions back from the HODs as to which programs should be recorded

- create a timetable for each week showing programs to be recorded, the library aide then recorded each program as they were broadcast,

- librarians preferred to use short tapes for each individual program so that each can be accessed separately from others in the series,

- the tapes were labelled and given accession numbers and added to the library shelves.

In instances where programs were not selected for recording library staff usually recorded the first couple of programs and previewed them to check for suitability. If the tapes appeared promising, they were sent to the HODs for review to ensure that they really were not wanted. Many extra requests for taping occurred through this process. Some librarians used their own judgement having checked the content of some programs. They chose to proceed with recording and to include the tapes within their resource base for possible future use by others. The recording process became very streamlined within the schools. In some instances, the schools were recording up to 20 programs from PET per week. Apart from taping the organisation included the need for recording details and adding these to the reference system. All tasks associated with PET were undertaken by existing staff within the schools.

No programs were viewed live. This was despite the fact that some of the programs were being broadcast live to air and with an interactive element in their instructional design. Although there were instances within the schools, where these programs were of particular interest to staff, they could not be viewed live because broadcast times did not match class times.

\section{Quality of Delivery}

The MDS system performed very well in this trial project. The quality of the reception was judged to have been of an extremely high standard and the high quality of the reception was maintained through many different types of weather condition. Several schools reported minor troubles with the receiving dishes. In one instance, heavy rain had seeped through the roof and interfered with the cabling. In another instance, vandals had been 
playing on the roof and interfered with the dish. The maintenance and support provided by the installation company was excellent, and the prompt and immediate service meant very few programs were missed as a result of technical problems.

Technical problems experienced with delivering the programs resulted in several instances where programs did not start at the exact time stated in the guide. In instances where schools were using automatic recording devices with pre-set times, this caused parts of the recordings to be missed. The problem drew attention to the need for very precise timing and a fail safe system to guarantee the total integrity of the system. In instances where schools required back-up copies of programs that were missed, these were able to be obtained from Edith Cowan University Media Centre at a nominal fee. This service was used by a number of schools and proved to be a substantial burden on the resources of the University. While the service was greatly appreciated by schools, the provision of such a service needs to be reviewed to maintain the costeffectiveness of the project.

\section{Program Implementation}

The responses from the participating schools were very positive about Stage One. Some of the more common responses related to:

- Cost. This was judged to be very reasonable. A school could purchase 20 commercial titles for the cost incurred with the project. This project delivered nearly 200 episodes with most schools finding over 100 of these to be ideally suited to their needs.

- Programming. The senior college schools liked the majority of programs due to a wish to establish open learning centres. Other schools preferred the more visual and topical programs. They stock their libraries with easy to read and informative print-based materials and prefer a similar style of video.

- Preferred Titles. Many of the programs were described as terrific. In particular, Science and Architecture, Art, Mechanical Universe, Fabric and Sewing and Nature Watch, Live Science. Less popular generally were Statistics, Computing, Nature Watch, Geography and Professional Development for Teachers.

- Program Formats. There was a mixed response to program formats. Some schools liked the talking-head programs, some didn't. In one school, the computing teacher made instructional materials to accompany the Computing lessons. In other schools, this program was seen as totally unsatisfactory. The senior colleges saw great value in the Business episodes while others rated this program lowly. 
The wide ranging responses from the schools on the suitability of the programs offered, indicated the need for future stages of the Project to consult with schools in the selection of programs to ensure maximum compatibility with the needs of all. No one participant could or should expect that all programs will be suitable. The trick will be to create a set of programs that together provide for the needs of all schools and that provide the highest level of overlap between the needs and interests of the schools.

\section{Suggestions from Schools}

Interviews with the stakeholders in the schools provided information that could help to improve the utility and usefulness of the Project in future planning. Some of the issues that schools suggested could be used to improve the service included:

- Early Viewing Guide. Schools required a significant level of lead time between receiving the list of planned programs and the date when broadcasting commences. Staff need to distribute the planned programs to HODs and to receive feedback prior to the commencement of broadcast. The system used by PET had not provided comfortable levels of time for this process.

- Subject summaries in the viewing guide. The list of broadcast programs was distributed to the schools in presentation sequence. Since schools needed to show the programs by subject to HODs, it was seen as a good idea to provide this form of programming with the viewing guide.

- Intervals Between Programs. In a similar manner to commercial television, the PET Project provided a continuous broadcast. Since most of the programs were being recorded, schools found that the lack of a gap between programs was an impediment to the recording process. Schools needed time to remove cartridges from machines and to insert new ones. The schools suggested that this needed consideration in planning the delivery times.

\section{Level of Classroom Use}

The real test of the success of the project must come from an assessment of the impact of the Project on the teaching and learning processes in the participating schools. By the completion of Stage One of the Project, most schools had recorded in excess of one hundred programs, all of which had been added to the video collections in the respective schools. An analysis of the usage of the videos at the end of Stage One revealed the following:

- Limited classroom applications. The tapes had not been widely used. although teachers had expressed very positive attitudes towards many of the tapes. Their reasons for low use were mainly due to a wish to review tapes before use and the curriculum constraints imposed by 
having already planned their teaching for the terms during which the new programs arrived.

- High levels of intended usage. Many teachers who had viewed the tapes expressed an intention to use them in 1994 classes. Many teachers were actively seeking alternative titles to those currently being used.

- Limited knowledge of availability. The administrators and library staff in a number of schools expressed regret at not having advertised the availability of the PET programs more widely. It was generally accepted that the Project had delivered some excellent teaching resources into the schools but maximum use had not been achieved because the information had not been passed in adequate detail to all those concerned.

- Expanded resource collections. In many schools, there was a level of satisfaction achieved by the significant increase of audio-visual materials to the resource collections. Many schools were keen for students and staff to see videos as valuable information resources for independent and resource-based learning activities. Although there had not been high levels of classroom use, the addition of the materials into the school resource base was viewed as a very positive outcome.

The responses from the schools indicated an acceptance on the part of all stakeholders that this form of educational television delivery was useful and a valuable complement to existing resource supply. There were no negative views expressed towards the process of implementing a strategy to receive and implement what was ostensibly educational pay TV. This suggested that more widespread use and application could be forthcoming if and when the PET Project extended its operation and offered the service more broadly across Perth secondary schools.

Another test for the success of the system was achieved by the number of schools electing to remain in the Project throughout 1994. By the end of Stage One, staff at the media centre had managed to obtain the cooperation of a number of program publishers and had put together a strong program for 1994. All schools in Stage One indicated a willingness to participate in the second stage as had a number of other schools who had heard about the project from the participants.

\section{Centennial Park}

The PET Project was unexpectedly carried a little further than to local schools by its inclusion in the programming selection for the Centennial Park Project. This project coordinated by Telstra involved the delivery of cable-TV on a trial basis to a suburb in Sydney. Homes were provided with the necessary telecommunications links to receive a number of channels of cable television including $\mathrm{CNN}, \mathrm{ABC}$, SBS, NASA, some Japanese programming and PET. The selection of PET as a channel in this trial gives strength to the claim of its creators that it is the first instance of 
educational pay-TV in Australia. The only reservation to this claim is that no viewers have yet had to pay for the service.

\section{Summary and conclusions}

The question of self-sustainability is an important consideration in the planning of a project of this nature. All functions of the PET Project were carried out with minimal costs to the users and minimal returns to the commercial players. The trial demonstrated that the technology is robust and that the service is useful and feasible from a commercial sense. The project also demonstrated a reasonable level of demand and use for the programs delivered through PET. Schools judged there to be appropriate educational benefit to be derived from the increased access to educational television that was provided. Details of the educational benefit are more as a consequence of the chosen programs than the MDS delivery method.

There appears no reason why the project could not become self sustaining. If the project were to continue at the same level with full cost recovery, the level of costs that would need to be met are shown in Figure 1.

\begin{tabular}{ll}
\hline Media technician & $\$ 15,000$ \\
Transmission costs & $\$ 10,000$ \\
Program royalties & $\$ 40,000$ \\
Administration costs & $\$ 10,000$ \\
\hline
\end{tabular}

Figure 1: Commercial costs for one year of program delivery via MDS

Schools electing to join the project would need to pay an up-front fee of $\$ 1200$ for the receiving equipment. If 100 schools participated in the project, the annual recurrent costs would be in the vicinity of $\$ 750$ per school. Of course the larger the number of schools, the smaller this amount would become. It might even be possible to run the project at a profit. Discussions with school administrators and resource personnel suggest that these levels of costs in larger secondary schools are not beyond reasonable bounds. The value received for money in terms of increased and broadened levels of resourcing further strengthens the project's viability.

The question of whether the system could become self-sustaining in a commercial sense in the local setting, is difficult to answer. There are only limited numbers of schools in the Perth metropolitan area and for the project to be able to pay its bills at full commercial rates would require high levels of participation. What Stage One of this project has shown is that the use of MDS is a viable means to organise a pay-TV approach to delivering educational resources to metropolitan schools and colleges. With appropriate levels of planning, educational support and promotion, there is no reason why a project like PET could not play an important and integral role in the provision of educational television to schools. 


\section{References}

Bahr, K. (1993). Delivering pay TV the MDS way. Australian Electronics Engineering, 72-75.

Batra, N. (1987). The Hour of Television: Critical Approaches. Methuen, NJ: The Scarecrow Press, Inc.

Bates, A. (1988). Television, learning and distance education. Journal of Educational Television, 14(3), 213-225.

Catchpole, M. (1993). Interactive media: the bridge between distance and classroom education. In T. Nunan (Ed.), Distance Education Futures. Adelaide: University of South Australia.

Clark, R. (1983). Reconsidering research on learning from media. Review of Educational Research, 53, 445-459.

Cuban, L. (1986). Teachers and machines: The classroom use of technology since 1920. New York. New York: Teachers College Press.

Forsslund, T. (1991). Factors that influence the use and impact of educational television in school. Journal of Educational Television, 17(1), 15-30.

Herrington, J. (1993). Television in education. In J. Herrington (Eds.), Using Television and video conferencing (pp. 1-10). Perth: WADEC.

Holifield, M. (1992). Reflective TV viewing: A course proposal. The High School Journal, 75(3), 191-196.

Honig, S. (1983). Television and the young children. Young Children, 63-74.

Kozma, R. (1991). Learning with media. Review of Educational Research, 61 (2), 179-211.

Moss, R., Gunter, B. \& Jones, C. (1991). Teachers using television. Journal of Educational Television, 17(2), 109-112.

Ornstein, A. (1990). Bringing telecommunications and videos into the classroom. The High School Journal, 73(4), 252-257.

Postman, N. (1984). The disappearance of Childhood. New York: Delacorte Press.

Salomon, G. (1984). Television is 'easy' and print is 'tough': The differential investment of mental effort in learning as a function of perceptions and attributions. Journal of Educational Psychology, 76, 647-658.

Sumner, H. (1991). BBC Education: the effectiveness and evaluation of educational broadcasting. Journal of Educational Television, 17(3), 159-172.

Witt, J. (1979). A Kid's TV Guide. Waco: Educational Production Division, Word Inc.

Authors: Ron Oliver is the Director of the Interactive Technology Research project at ECU, where Mike Grant is Head of Media Services. Mike has trialed many innovative projects using telecommunications in the delivery of educational media. Geoff Younger is manager of media engineering at ECU and coordinated this project. Address: Edith Cowan University, 2 Bradford St, Mt Lawley, WA 6050. (09) 3706372 Email r.oliver@cowan.edu.au

Please cite as: Oliver, R., Grant, M. and Younger, G. (1994). The Perth Educational Television Project. Australian Journal of Educational Technology, 10(1), 27-40. http: / / www.ascilite.org.au / ajet / ajet10 / oliver.html 